\title{
A novel BN supported bi-metal catalyst for selective hydrogenation of crotonaldehyde
}

\author{
Jeffrey C.S. Wu* Wei-Chih Chen \\ Department of Chemical Engineering, National Taiwan University, Taipei, Taiwan 10617, ROC
}

Received 25 November 2004; received in revised form 21 April 2005; accepted 27 April 2005

Available online 13 June 2005

\begin{abstract}
A series of boron nitride (BN) supported Pt-Sn catalysts was prepared with a co-incipient wetness method employing hexachloroplatinic acid and tin(II) chloride. Pt loading was fixed at $1.1 \mathrm{wt} \%$; Sn loading varied from 0.25 to $0.75 \mathrm{wt} \%$ on BN support. Selective hydrogenation of gas-phase crotonaldehyde was conducted in a steady-state flow reactor with temperatures ranging from 40 to $100{ }^{\circ} \mathrm{C}$. The selectivity of crotyl alcohol reached over $80 \%$. An optimum yield of crotyl alcohol reached $38 \%$ at $60 \%$ conversion of crotonaldehyde at $80{ }^{\circ} \mathrm{C}$ using Pt-Sn $(0.75) /$ $\mathrm{BN}$ catalyst, while Pt-Sn(0.75)/ $\gamma-\mathrm{Al}_{2} \mathrm{O}_{3}$ yielded less crotyl alcohol and a lower rate of crotonaldehyde conversion. The maximum yield rate of crotyl alcohol was $2.4 \mathrm{mmol} /\left(\mathrm{g}\right.$-cat. h) at $80{ }^{\circ} \mathrm{C}$. Negligible deactivation was found during reaction for $4-6 \mathrm{~h}$. The crystalline phases of PtSn and $\mathrm{SnPt}_{3}$ alloys were observed from the XRD spectra of Pt-Sn/BN catalysts with various Sn loadings. The selectivity of crotyl alcohol increased with $\mathrm{Sn}$ loadings but the activity values of the catalysts went through a maximum. $\mathrm{The}_{2}$ reduction at $300{ }^{\circ} \mathrm{C}$ gave an optimum $\mathrm{Pt}-$ Sn alloy particle size so that the selectivity of crotyl alcohol increased without losing catalyst activity. The $\mathrm{C}=\mathrm{O}$ bond of crotonaldehyde was preferentially hydrogenated and the hydrogenation of $\mathrm{C}=\mathrm{C}$ bond was suppressed, resulting in the increase of crotyl alcohol selectivity. (C) 2005 Elsevier B.V. All rights reserved.
\end{abstract}

Keywords: Pt-Sn/BN catalyst; Non-oxide support; Selective hydrogenation; Crotonaldehyde

\section{Introduction}

The selective hydrogenation of an $\alpha, \beta$-unsaturated aldehyde into an unsaturated alcohol is an important process in the pharmaceutical, fine chemicals and fragrance industries [1]. However, the hydrogenation of the $\mathrm{C}=\mathrm{C}$ bond is thermodynamically favorable over the $\mathrm{C}=\mathrm{O}$ bond, which leads to the undesirable product, saturated aldehydes. Improved selectivity for unsaturated alcohols was achieved by using reducible supports or additive promoter [2-5]. Supported bimetallic Pt-Sn catalyst was also suggested to be an effective catalyst for the selective hydrogenation of $\alpha, \beta-$ unsaturated aldehyde into an unsaturated alcohol, such as crotonaldehyde to crotyl alcohol [6,7].

Materials traditionally used as supports are insulating oxides such as $\mathrm{SiO}_{2}, \gamma-\mathrm{Al}_{2} \mathrm{O}_{3}$, silica-alumina and various

\footnotetext{
* Corresponding author. Tel.: +886 223631994; fax: +886 236323040 .

E-mail address: cswu@ntu.edu.tw (Jeffrey C.S. Wu).
}

zeolites. These oxides possess large surface area, numerous acidic/basic sites and metal-support interaction that offer particular catalytic activity for many reactions. Metal oxides have also been thoroughly studied and employed in the chemical industry for decades.

The graphite-like hexagonal boron nitride $(\mathrm{BN})$ is the most stable BN isomer under ambient conditions [8]. Boron nitride has large thermal conductivity, superior temperature stability and acid-base resistance. In general, BN is inert material for catalytic reaction. In a supported metal system such as $\mathrm{Pt} / \mathrm{BN}, \mathrm{BN}$ has been shown to have a negligible interaction with $\mathrm{Pt}$ and support in the catalytic oxidation. Boron nitride allows a possibility to reduce the Pt or Snsupport interaction. The easy migration of $\mathrm{Pt}$ particles occurred on the crystalline face of $\mathrm{BN}$ due to the weaker bonding between the crystalline face and Pt $[9,10]$. Such effect may promote the Pt-Sn sintering and lead to the formation of PtSn alloy, a favorable phase for the selective hydrogenation of $\alpha, \beta$-unsaturated aldehyde into unsatu- 
rated alcohol [6]. We therefore choose crotonaldehyde hydrogenation as a probing reaction to investigate the unique catalytic property provided by a novel BN support. The effects of the Sn addition on the surface characteristics and properties of $\mathrm{Pt}$ were explored in relation to the activity/ selectivity of the catalysts for the hydrogenation of the $\mathrm{C}=\mathrm{O}$ and $\mathrm{C}=\mathrm{C}$ bonds in the vapor phase hydrogenation of crotonaldehyde. The effects of $\mathrm{Sn}$ loadings and $\mathrm{H}_{2}$ reduction temperatures were also examined.

\section{Experimental}

\subsection{Catalyst preparation}

Hexagonal-BN was obtained from High Performance Materials Inc. (Taiwan). It was crystallized at roughly $800{ }^{\circ} \mathrm{C}$ during synthesis, a temperature lower than the typical $1000{ }^{\circ} \mathrm{C}$. Gamma alumina $\left(\gamma-\mathrm{Al}_{2} \mathrm{O}_{3}\right)$, a commonly used oxide support, was obtained from Merck (USA) and used for comparison. Precursor salt, $\mathrm{H}_{2} \mathrm{PtCl}_{6} \cdot 6 \mathrm{H}_{2} \mathrm{O}$, with approximately $40 \mathrm{wt} \%$ platinum, and pure $\mathrm{SnCl}_{2}$ were purchased from Alfa Aesar (USA). Methanol was chosen as the diluting solvent for improved soaking of the hydrophobic BN support. The supported Pt-Sn catalysts were prepared utilizing a co-incipient wetness method. The quantity of methanol required to completely fill the support's pore volume was predetermined. Calculated amounts of $\mathrm{Pt}$ and $\mathrm{Sn}$ precursor salts were dissolved together in methanol to obtain the desired metal loadings. After the co-incipient wetness process was applied, catalysts were air-dried at room temperature for $24 \mathrm{~h}$, these are referred to as fresh catalysts. All Pt loading was fixed at $1.1 \mathrm{wt} \%$, Sn loadings varied from 0.25 to $0.75 \mathrm{wt} \%$. The $\mathrm{X} . \mathrm{XX}$ wt\% of Sn loading was assigned as Pt-Sn(X.XX)/BN. In addition, $1.1 \mathrm{wt} \% \mathrm{Pt} / \mathrm{BN}, 1.1 \mathrm{wt} \% \mathrm{Pt} / \gamma-\mathrm{Al}_{2} \mathrm{O}_{3}$ and $\mathrm{Pt}-\mathrm{Sn} /$ $\gamma-\mathrm{Al}_{2} \mathrm{O}_{3}$ catalysts were also prepared for comparison. The detailed incipient wetness procedure is described in the literature [11].

\subsection{Characterization}

The specific surface area of the support was measured by $\mathrm{N}_{2}$ adsorption in Micromeritics ASAP 2010. The particle sizes and distributions of $\mathrm{BN}$ and $\mathrm{Al}_{2} \mathrm{O}_{3}$ were measured by laser-light scattering. $\mathrm{Al}_{2} \mathrm{O}_{3}$ was suspended and dispersed ultrasonically in water for $3 \mathrm{~min}$. BN was dispersed in ethanol due to its hydrophobicity. Coulter LS 230 was used to measured the scattering of incidental light at the $90^{\circ}$ positions, and then the particle size was calculated using the Fraunhofer equation. Fresh catalyst was reduced in $\mathrm{H}_{2}$ flow at $300{ }^{\circ} \mathrm{C}$ for $2 \mathrm{~h}$ before chemisorption. The $\mathrm{H}_{2}$ chemisorption procedures were similar to those described by Yang and Goodwin [12]. The amount of irreversible $\mathrm{H}_{2}$ chemisorption was taken to determine the $\mathrm{Pt}$ dispersion. A transmission electron microscope (TEM, Hitachi H-7100) was employed to observe the shape of $\mathrm{BN}$ and the appearance of $\mathrm{Pt}-\mathrm{Sn}$ particles dispersed on the support. $\mathrm{Pt}-\mathrm{Sn} / \mathrm{Al}_{2} \mathrm{O}_{3}$ or $\mathrm{Pt}-\mathrm{Sn} / \mathrm{BN}$ was dispersed ultrasonically in ethanol for $30 \mathrm{~min}$, and then a small portion was taken from the top of the catalystsuspended solution and dropped on a copper mesh. The particles adhered on the copper wire in the mesh after drying, and then the mesh was transported to the TEM chamber for analysis. The crystalline phases of Pt-Sn/BN were identified by X-ray diffraction (XRD). The XRD equipment, type M03XHF22 from the Material Analysis and Characterization Company, was operated at $40 \mathrm{kV}$, with a $1.54056 \AA \mathrm{X}$-ray wavelength from a $\mathrm{Cu}$ target, and a scanning speed of $0.5^{\circ} / \mathrm{min}$. The reduction of fresh Pt-Sn catalyst was studied using the temperature programmed reduction (TPR). The gas used in TPR was a mixture of $5 \mathrm{vol} \% \mathrm{H}_{2}$ in Ar. A fresh catalyst was loaded into a quartz tube and purged with $\mathrm{N}_{2}$. The gas was then switched to the $\mathrm{H}_{2} / \mathrm{Ar}$ mixture at room temperature. The TPR was performed in the $\mathrm{H}_{2} / \mathrm{Ar}$ mixture from 50 to $600{ }^{\circ} \mathrm{C}$ at a constant heating rate of $10^{\circ} \mathrm{C} / \mathrm{min}$.

\subsection{Catalytic reaction}

Fresh catalyst $(0.3 \mathrm{~g})$ was charged in the middle of a straight-tube quartz reactor with a $16 \mathrm{~mm}$ i.d. The catalyst was reduced for $2 \mathrm{~h}$ at 200,300 or $450{ }^{\circ} \mathrm{C}$, using pure hydrogen $(99.999 \%)$ in the reactor and then cooled to $40{ }^{\circ} \mathrm{C}$ before switching to the reactant mixture. The reactant mixture was composed by flowing pure hydrogen into a saturator filled with liquid crotonaldehyde. Crotonaldehyde (98\%) was purchased from Fluka. The concentration of crotonaldehyde in the reactant mixture was adjusted by tuning the saturator temperature, and the concentration was further confirmed by an on-line GC before reaction. The molar ratio of $\mathrm{H}_{2}$ /crotonaldehyde mixture was maintained at 59 and passed through the reactor at $50 \mathrm{ml} / \mathrm{min}$ under atmospheric pressure. The reaction temperature was increased from 40 to $100{ }^{\circ} \mathrm{C}$ in a tubular furnace. A thermocouple was placed in the center of the catalyst bed to record the reaction temperature and to control the furnace. All gas lines were wrapped in heating tape and kept warm to prevent condensation. The products of crotonaldehyde hydrogenation were measured by an on-line GC (HP GC6890) equipped with a $30 \mathrm{~m} \mathrm{HP-}$ Innowax capillary column using a flame ionization detector. The activities of Pt-Sn catalyst were measured after achieving steady-state at $40{ }^{\circ} \mathrm{C}$. It took about $30 \mathrm{~min}$ to obtain steady-state conversion. The reaction temperature was then raised to 60,80 and $100{ }^{\circ} \mathrm{C}$ to investigate the variations of conversion and product selectivity. Normally an entire reaction took 4-6 h to evaluate a fresh catalyst without noticeable deactivation. The same hydrogenation reaction conducted on $\mathrm{Sn} / \mathrm{BN}$ catalyst and $\mathrm{BN}$ support found no activity up to $100{ }^{\circ} \mathrm{C}$. The conversion of crotonaldehyde and the selectivity of product were calculated using Eqs. (1) and (2). The yield of crotyl 
alcohol was calculated by multiplying the conversion by its selectivity and dividing by $100 \%$.

$$
\begin{aligned}
\text { conversion }(\%)= & \frac{C_{\text {crotonaldehyde }} \text { Input }-C_{\text {crotonaldehyde }} \text { Output }}{C_{\text {crotonaldehyde }} \text { Input }} \\
& \times 100 \%
\end{aligned}
$$

$$
\begin{aligned}
\text { selectivity }(\%)= & \frac{C_{\text {product }}}{C_{\text {crotonaldehyde }} \text { Input }-C_{\text {crotonaldehyde }} \text { Output }} \\
& \times 100 \%
\end{aligned}
$$

\section{Results and discussion}

The specific surface area of $\mathrm{BN}$ and $\gamma-\mathrm{Al}_{2} \mathrm{O}_{3}$ were 47.5 and $116 \mathrm{~m}^{2} / \mathrm{g}$, respectively. The particle sizes of $\mathrm{BN}$ were in the range 0.4 and $90 \mu \mathrm{m}$ and that of $\gamma-\mathrm{Al}_{2} \mathrm{O}_{3}$ was 6-190 $\mu \mathrm{m}$. The mean particle size of $\mathrm{BN}$ and $\gamma-\mathrm{Al}_{2} \mathrm{O}_{3}$ were calculated to be 2.8 and $66.4 \mu \mathrm{m}$, respectively. Table 1 summarizes the results of $\mathrm{H}_{2}$ chemisorption on $\mathrm{Pt} / \mathrm{BN}$ and $\mathrm{Pt}-\mathrm{Sn} / \mathrm{BN}$ series catalysts. The small amount of $\mathrm{H}_{2}$ chemisorption on $\mathrm{Pt} / \mathrm{BN}$ was due to poor $\mathrm{Pt}$ dispersion as a result of sintering. The various amounts of $\mathrm{H}_{2}$ chemisorption on three Pt-Sn/BN catalysts might be just due to the different $\mathrm{Pt}$ dispersions among these catalysts during the preparation. In addition, the amounts of hydrogen chemisorption of $\mathrm{Pt}-\mathrm{Sn}(0.5) / \mathrm{BN}$ and $\mathrm{Pt}-\mathrm{Sn}(0.75)$ were suppressed due to the Sn dilution of the surface $\mathrm{Pt}$.

Fig. 1 shows the XRD spectra of Pt-Sn/BN catalysts, which were $\mathrm{H}_{2}$ reduced at $300{ }^{\circ} \mathrm{C}$. The spectrum of $\mathrm{Sn} / \mathrm{BN}$ was the same as that of pure BN. No characteristic peak of Sn was found; this absence indicated that either individual Sn particles did not exist or were very small in size. The major characteristic peaks of Pt are clearly shown at $39.8^{\circ}$ and $46.2^{\circ}$. The crystalline phases of $\mathrm{PtSn}$ and $\mathrm{SnPt}_{3}$ alloys were also observed with various Sn loading catalysts. The characteristic peaks of $\mathrm{SnPt}_{3}$ were at $38.9^{\circ}$ and $45.0^{\circ}$ on all $\mathrm{Pt}-\mathrm{Sn} / \mathrm{BN}$ series catalysts. In addition to $\mathrm{SnPt}_{3}, \mathrm{Pt}-\mathrm{Sn}(0.75) /$ $\mathrm{BN}$ also contained the PtSn crystalline at peaks of $30.1^{\circ}$ and $62.5^{\circ}$ [13]. The rest of the characteristic peaks of $\mathrm{SnPt}_{3}$ or PtSn were not marked because they were overlapped with those of Pt or BN. A small portion of Pt particles can be found on Pt-Sn(0.25)/BN, as shown in its XRD spectrum.

Table 1

Hydrogen chemisorption of BN supported metal catalysts

\begin{tabular}{lllll}
\hline Catalyst & $\mathrm{Pt}(\mathrm{wt} \%)$ & $\mathrm{Sn}(\mathrm{wt} \%)$ & $\begin{array}{l}\text { Hydrogen atom } \\
(\mu \mathrm{mol} / \mathrm{g} \text {-cat. })\end{array}$ & $\mathrm{H} / \mathrm{Pt}$ \\
\hline $\mathrm{Pt} / \mathrm{BN}$ & 1.1 & 0.00 & 3.2 & 0.058 \\
$\mathrm{Pt}-\mathrm{Sn}(0.25) / \mathrm{BN}$ & 1.1 & 0.25 & 6.2 & 0.110 \\
$\mathrm{Pt}-\mathrm{Sn}(0.50) / \mathrm{BN}$ & 1.1 & 0.50 & 1.2 & 0.021 \\
$\mathrm{Pt}-\mathrm{Sn}(0.75) / \mathrm{BN}$ & 1.1 & 0.75 & 4.0 & 0.071 \\
\hline
\end{tabular}

${ }^{\mathrm{a}}$ Catalysts $\mathrm{H}_{2}$ reduced at $300{ }^{\circ} \mathrm{C}$ for $2 \mathrm{~h}$ before chemisorption.

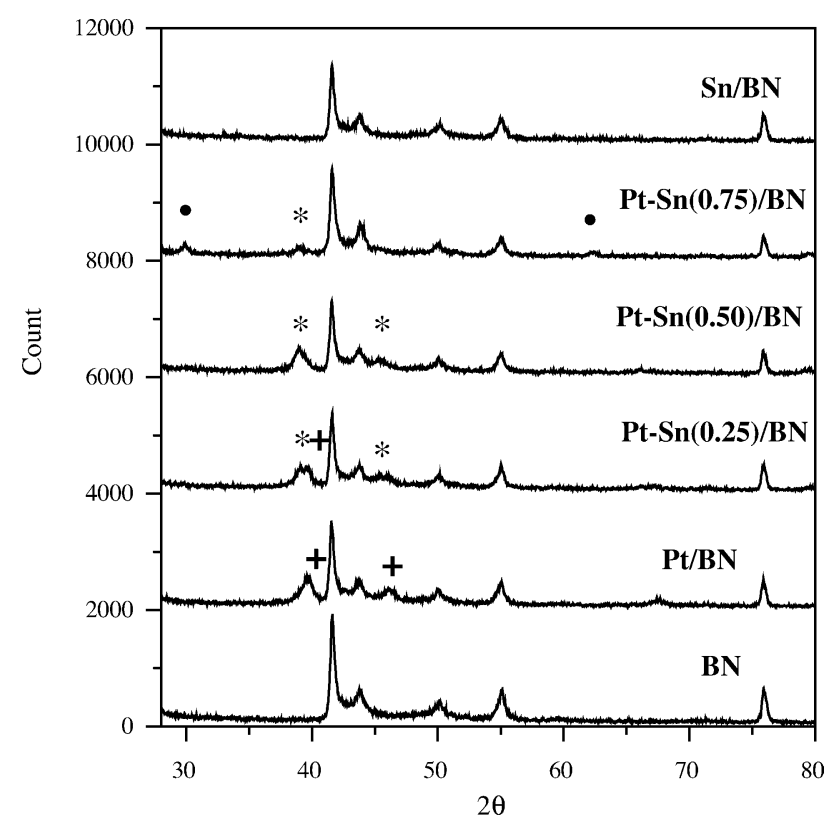

Fig. 1. XRD spectra of Pt-Sn/BN catalysts $\mathrm{H}_{2}$ reduced at $300^{\circ} \mathrm{C},(+) \mathrm{Pt},(*)$ SnPt3 and (•) PtSn.

With a higher Sn loading, such as Pt-Sn(0.5)/BN and Pt$\mathrm{Sn}(0.75) / \mathrm{BN}$, the characteristic peaks of Pt were diminished, indicating that no individual $\mathrm{Pt}$ particles were present. Therefore, the PtSn and/or $\mathrm{SnPt}_{3}$ alloy were formed during the $\mathrm{H}_{2}$ reduction. The $\mathrm{SnPt}_{3}$ particles of $\mathrm{Pt}-\mathrm{Sn}(0.5) / \mathrm{BN}$ were approximately $8.9 \mathrm{~nm}$, as calculated by the Scherrer equation.

The XRD spectra (not shown) of Pt/ $\gamma-\mathrm{Al}_{2} \mathrm{O}_{3}$ and $\mathrm{Pt}-\mathrm{Sn} / \gamma$ $\mathrm{Al}_{2} \mathrm{O}_{3}$ series catalysts reduced at $300{ }^{\circ} \mathrm{C}$ were the same as the background spectra of $\gamma-\mathrm{Al}_{2} \mathrm{O}_{3}$. The metal particles were

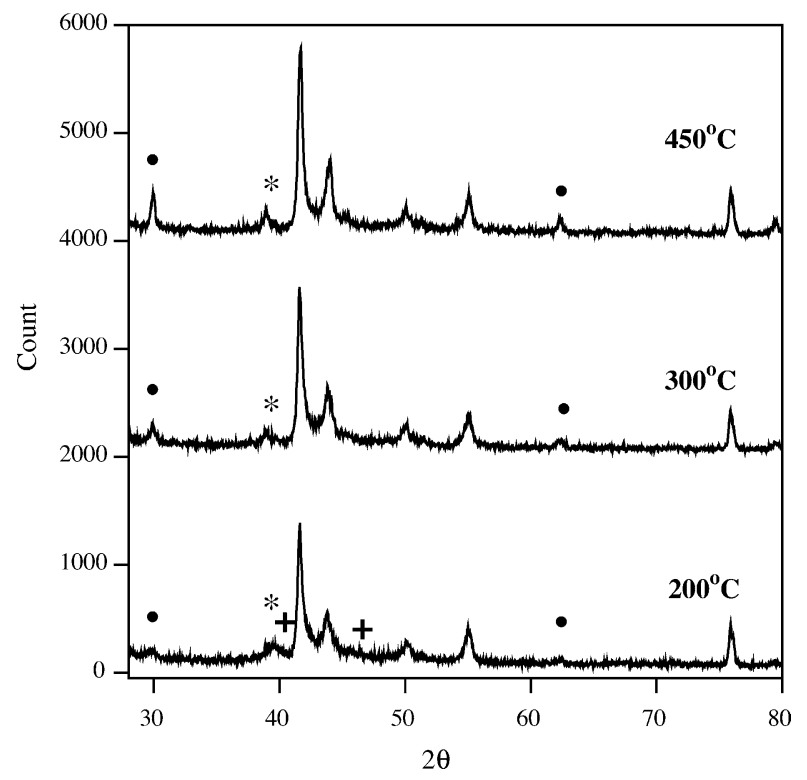

Fig. 2. XRD spectra of $\mathrm{Pt}-\mathrm{Sn}(0.75) / \mathrm{BN}$ catalyst $\mathrm{H}_{2}$ reduced, (+) $\mathrm{Pt},\left(^{*}\right)$ SnPt3 and $(\bullet)$ PtSn. 


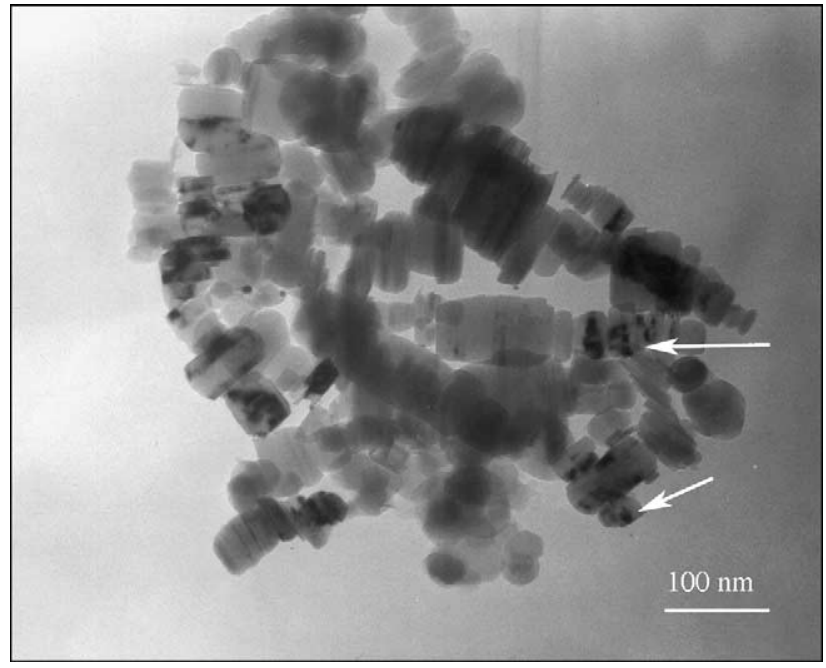

Fig. 3. TEM micrograph of Pt-Sn(0.75)/BN catalyst.

too small to be observed in the $\mathrm{XRD}$, revealing highly dispersed $\mathrm{Pt}$ and/or Pt-Sn particles on the $\gamma-\mathrm{Al}_{2} \mathrm{O}_{3}$ support. The effect of the $\mathrm{H}_{2}$ reduction temperature on $\mathrm{Pt}-\mathrm{Sn}(0.75)$ / $\mathrm{BN}$ is shown in Fig. 2. The $\mathrm{PtSn}$ and $\mathrm{SnPt}_{3}$ alloys were formed, as their respective characteristic peaks of XRD can be easily found. A portion of pure Pt crystalline phase was formed at a reduction temperature of $200{ }^{\circ} \mathrm{C}$, but diminished at higher reduction temperatures. $\mathrm{Pt}$ and $\mathrm{Sn}$ were sintered to $\mathrm{Pt}-\mathrm{Sn}$ alloy with increasing reduction temperatures due to metal migration on BN surface. Fig. 3 shows the TEM micrograph of Pt-Sn(0.75)/BN. Some of the metal particles with sizes $8-15 \mathrm{~nm}$ can be observed in the TEM micrograph, which indicates that most of the Pt-Sn particles were located on the edges of BN particles.

Fig. 4 depicts the reaction paths of $\alpha, \beta$ hydrogenation on crotonaldehye. The products are crotyl alcohol or butyraldehyde via $\mathrm{C}=\mathrm{O}$ or $\mathrm{C}=\mathrm{C}$ hydrogenation, respectively. Butyraldehyde is thermodynamically favorable in crotonaldehyde hydrogenation based on Gibbs free energy calculation. The end product is butanol with further hydrogenation. Fig. 5 shows the conversions of crotonaldehyde hydrogenation and the selectivities of crotyl alcohol using $\mathrm{Pt} / \mathrm{BN}$ and $\mathrm{Pt} / \gamma-\mathrm{Al}_{2} \mathrm{O}_{3}$ catalysts, respectively. While the selectivities of crotyl alcohol were within the same range

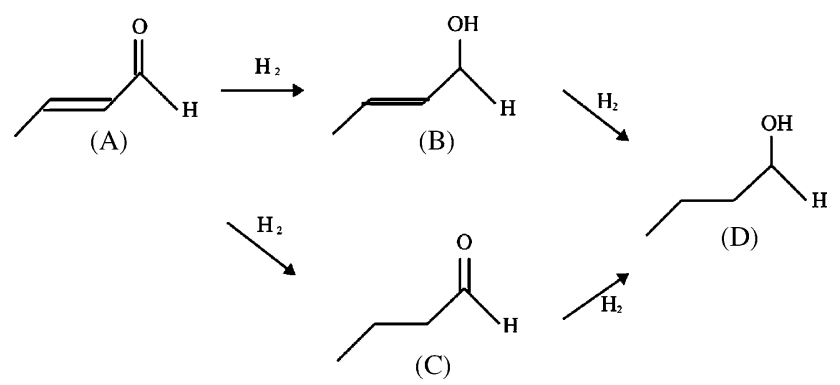

Fig. 4. The hydrogenation path of crotonaldehyde: (A) crotonaldehyde, (B) crotyl alcohol, (C) butyraldehyde and (D) butanol.

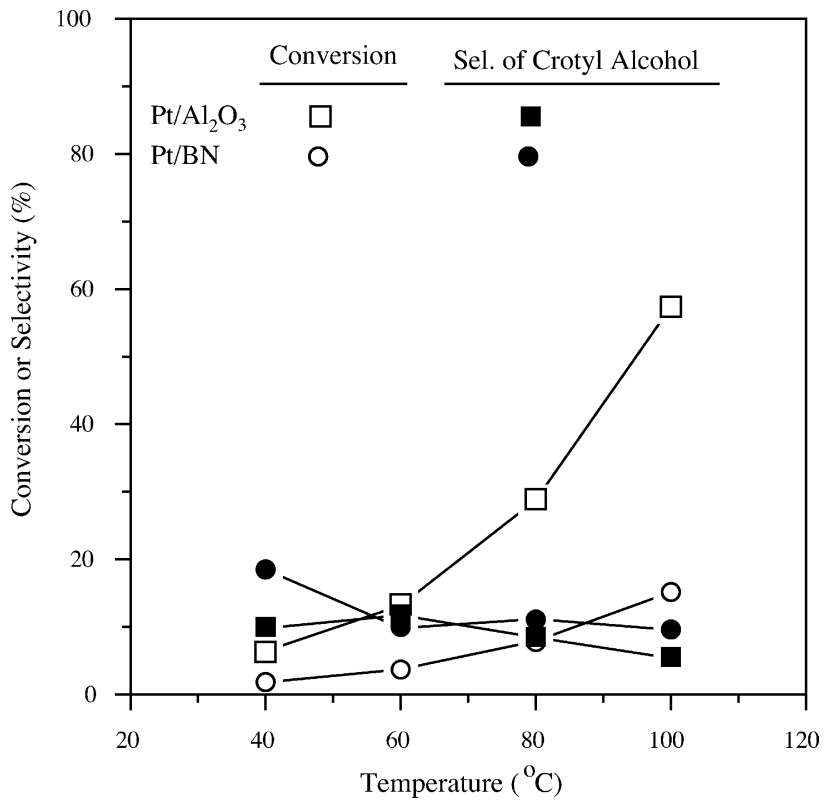

Fig. 5. Conversion of crotonaldehyde and selectivity of crotyl alcohol on Pt/ $\mathrm{BN}$ and $\mathrm{Pt} / \gamma-\mathrm{Al}_{2} \mathrm{O}_{3}$

(10-20\%), the Pt/BN gave much lower conversion (2-15\%) values compared to those of $\mathrm{Pt} / \gamma-\mathrm{Al}_{2} \mathrm{O}_{3}$. The low activity of $\mathrm{Pt} / \mathrm{BN}$ was obviously due to its poor Pt dispersion (Table 1). The crotonaldehyde conversion and the selectivity of crotyl alcohol were substantially increased on $\mathrm{Pt}-\mathrm{Sn}(0.75) / \mathrm{BN}$ under the same reaction conditions as shown in Fig. 6. The

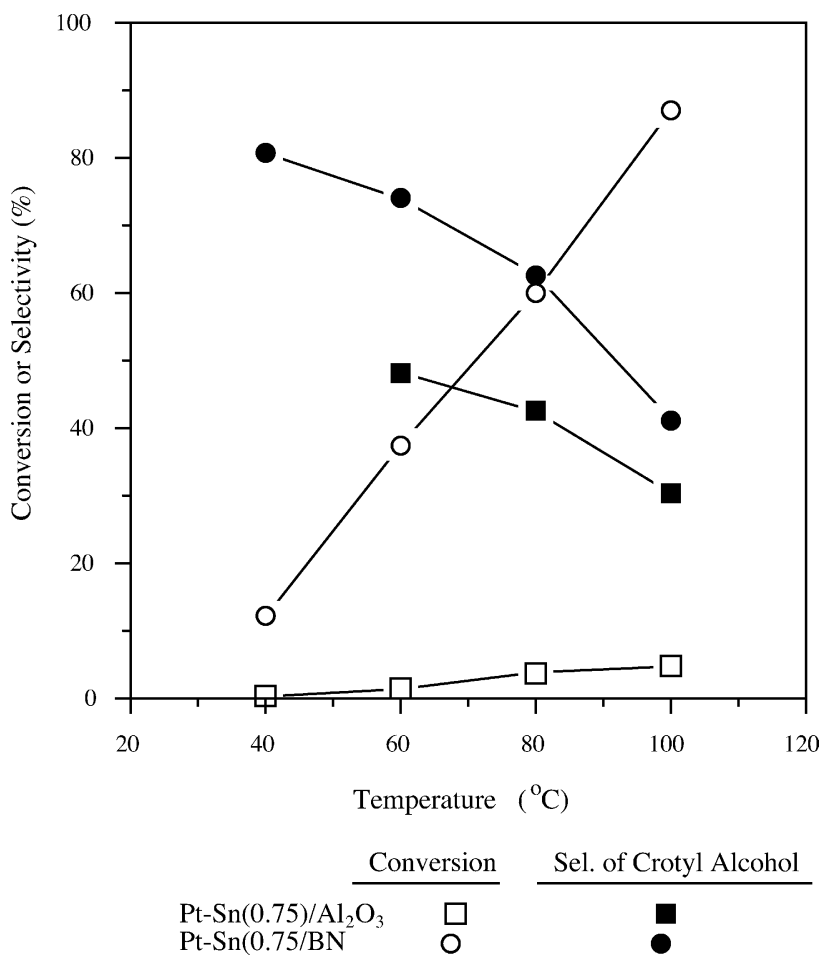

Fig. 6. Conversion of crotonaldehyde and selectivity of crotyl alcohol on $\mathrm{Pt}-\mathrm{Sn}(0.75) / \mathrm{BN}$ and $\mathrm{Pt}-\mathrm{Sn}(0.75) / \gamma-\mathrm{Al}_{2} \mathrm{O}_{3}$. 


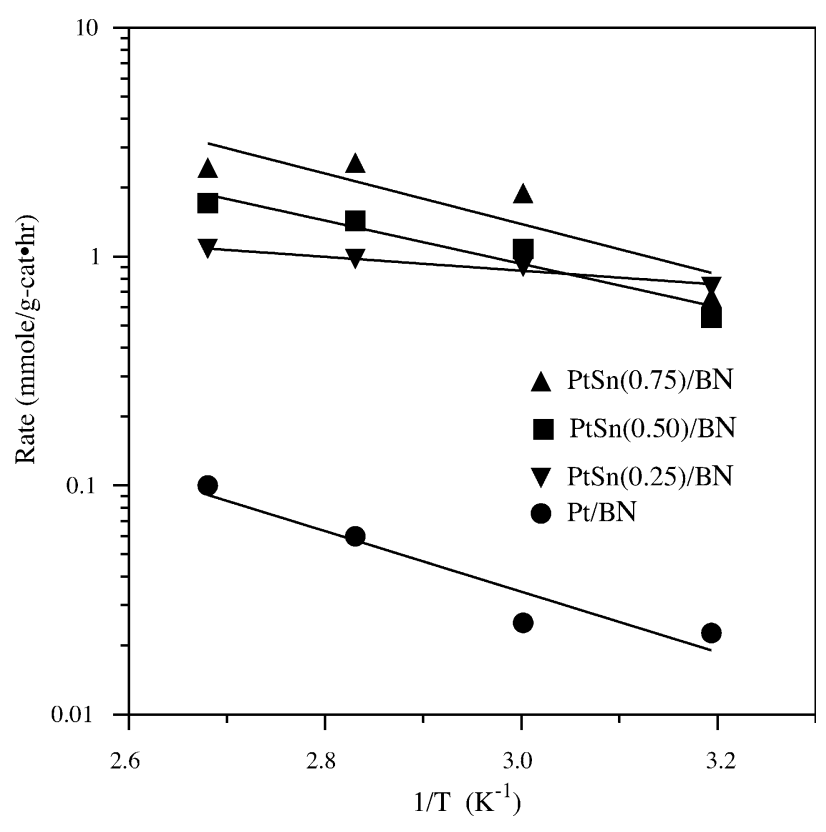

Fig. 7. Activities of $\mathrm{Pt} / \mathrm{BN}$ and $\mathrm{Pt}-\mathrm{Sn} / \mathrm{BN}$ series catalysts.

selectivity of crotyl alcohol was improved to over $80 \%$ at $40{ }^{\circ} \mathrm{C}$. The optimum yield of crotyl alcohol achieved $\sim 38 \%$ with a conversion $60 \%$ at $80{ }^{\circ} \mathrm{C}$. However, for Pt-Sn(0.75)/ $\gamma-\mathrm{Al}_{2} \mathrm{O}_{3}$, the conversion was significantly reduced to $0.3-$ $4.7 \%$ with the selectivity of crotyl alcohol ranging from 50 to $30 \%$ under the same reaction conditions (Fig. 6). The production rates of crotyl alcohol based on the unit weight of catalyst are shown in Fig. 7. The apparent activation energy is near $20 \mathrm{~kJ} / \mathrm{mol}$, calculated by using the Arrhenius equation. The maximum rate of crotyl alcohol was near $2.4 \mathrm{mmol} /\left(\right.$ g-cat. h) on $\mathrm{Pt}-\mathrm{Sn}(0.75) / \mathrm{BN}$ at $80^{\circ} \mathrm{C}$. To our knowledge, this is the highest rate of supported bi-metallic Pt-Sn catalysts currently reported in the literature [6,14-16].

The conversion and selectivity trends of the $\mathrm{Pt}-\mathrm{Sn} / \mathrm{BN}$ series catalysts at temperatures ranging from 40 to $100{ }^{\circ} \mathrm{C}$ were similar to those shown in Fig. 6. For simplicity, Table 2 summarizes the effect of Sn loadings on the product selectivities at a reaction temperature of $80{ }^{\circ} \mathrm{C}$. The conversion of crotonaldehyde increased as Sn loadings increased. Surprisingly, the selectivity of crotyl alcohol also increased resulting in its high yield. On the other hand, the selectivity of butyraldehyde decreased significantly as $\mathrm{Sn}$ loadings increased, while that of butanol remained within a narrow range. Thus, that the activity and the selectivity of crotyl alcohol increased simultaneously implies that not only is the rate of crotonaldehyde enhanced but also the hydrogenation of $\mathrm{C}=\mathrm{C}$ is significantly suppressed.

The influence of $\mathrm{H}_{2}$ reduction temperature on Pt$\mathrm{Sn}(0.75) / \mathrm{BN}$ was further studied and the results at a reaction temperature of $80^{\circ} \mathrm{C}$ are summarized in Table 3. The selectivities of crotyl alcohol increased as reduction temperatures increased. The $\mathrm{Pt}-\mathrm{Sn}(0.75) / \mathrm{BN}$ reduced at $300{ }^{\circ} \mathrm{C}$ gave the highest rate of conversion at $60.1 \%$. Conversion then fell with a higher reduction temperature of $450{ }^{\circ} \mathrm{C}$. Although the highest selectivity of crotyl alcohol occurred when Pt-Sn(0.75)/BN was reduced at $450{ }^{\circ} \mathrm{C}$, its decreased yield was due to its declining activity.

Activity and selectivity enhancement are attributed to the formation of $\mathrm{PtSn}$ and/or $\mathrm{SnPt}_{3}$ particles on $\mathrm{BN}$ support (Fig. 1). Only $\mathrm{SnPt}_{3}$ was found at $\mathrm{Sn}$ loadings below $0.5 \mathrm{wt} \%$. At higher $\mathrm{Sn}$ loadings, both $\mathrm{PtSn}$ and $\mathrm{SnPt}_{3}$ were found (Fig. 1). Consequently, the production rate of crotyl alcohol should be further enhanced due to PtSn alloy. The enhanced hydrogenation of the $\mathrm{C}=\mathrm{O}$ bond was due to the promoting effect of the oxidized Sn species [6]. The active sites might be in the boundary zone between $\mathrm{Pt}$ and tin oxide on the PtSn alloy. The high portion of PtSn alloy and surface $\mathrm{Sn}^{n+}$ with moderate levels of metal dispersion in Pt$\mathrm{Sn}(0.75) / \mathrm{BN}$ gave the best results for the selective hydrogenation of the $\mathrm{C}=\mathrm{O}$ bond in crotonaldehyde.

The $\mathrm{H}_{2}$ reduction of fresh $\mathrm{Pt}-\mathrm{Sn} / \mathrm{BN}$ catalysts were studied by employing TPR as shown in Fig. 8. The $\mathrm{H}_{2}$ consumption of all $\mathrm{Pt}-\mathrm{Sn} / \mathrm{BN}$ series catalysts were in the range of 120 to $\sim 180{ }^{\circ} \mathrm{C}$, while that of all $\mathrm{Pt}-\mathrm{Sn} / \gamma-\mathrm{Al}_{2} \mathrm{O}_{3}$ series catalysts were in a higher temperature range of 180 to $\sim 280{ }^{\circ} \mathrm{C}$ (not shown). The decomposition and/or reduction of $\mathrm{Pt}$ and $\mathrm{Sn}$ precursors at lower temperature indicate less metal-support interaction on $\mathrm{BN}$ than on $\gamma-\mathrm{Al}_{2} \mathrm{O}_{3}$. The tendency to form Pt-Sn particles was also much easier on BN than on $\gamma-\mathrm{Al}_{2} \mathrm{O}_{3}$ as shown in Figs. 1 and 2.

Boron nitride provides an inert and slippery surface that facilitates the formation of Pt-Sn alloy during $\mathrm{H}_{2}$ reduction due to the unrestrained migration of metal particles. On the other hand, $\gamma-\mathrm{Al}_{2} \mathrm{O}_{3}$ may constrain the mobility of $\mathrm{Pt}$ and $\mathrm{Sn}$ during $\mathrm{H}_{2}$ reduction due to the metal-support affinity, thus preventing the formation of Pt-Sn alloy particles. The size of Pt-Sn alloy particles is also an important factor to be considered because crotonaldehyde hydrogenation is struc-

Table 3

The Effect of $\mathrm{H}_{2}$ reduction on selective hydrogenation using $\mathrm{Pt}-\mathrm{Sn}(0.75) / \mathrm{BN}$ at reaction temperature $80{ }^{\circ} \mathrm{C}$

\begin{tabular}{llllll}
\hline Reduction Temperature $\left({ }^{\circ} \mathrm{C}\right)$ & Conversion $(\%)$ & Selectivity $(\%)$ & \multicolumn{2}{c}{ Yield (\%) $)^{\mathrm{a}}$ crotyl alcohol } \\
\cline { 2 - 5 } & & Crotyl alcohol & Butyraldehyde & Butanol \\
\hline 200 & 30.6 & 45.9 & 29.6 & 24.5 & 14.0 \\
300 & 60.1 & 62.7 & 9.1 & 28.1 & 37.7 \\
450 & 42.9 & 72.8 & 10.8 & 16.4 & 31.2 \\
\hline
\end{tabular}

Catalyst $\mathrm{H}_{2}$ reduced for $2 \mathrm{~h}$.

${ }^{\mathrm{a}}$ Yield $=$ conversion $\times$ selectivity $/ 100$. 
Table 2

The effect of $\mathrm{Pt} / \mathrm{Sn}$ ratio on the selective hydrogenation of crotonaldehyde at $80^{\circ} \mathrm{C}$

\begin{tabular}{|c|c|c|c|c|c|}
\hline Sn ratio & Conversion $(\%)$ & Crotyl alcohol & Selectivity (\%) butyraldehyde & Butanol & Yield $(\%)^{\mathrm{a}}$ crotyl alcohol \\
\hline 0 & 8.0 & 11.5 & 75.0 & 12.5 & 0.9 \\
\hline 0.25 & 53.1 & 27.1 & 35.2 & 37.5 & 14.4 \\
\hline 0.50 & 46.8 & 44.4 & 27.4 & 28.2 & 20.8 \\
\hline 0.75 & 60.1 & 62.7 & 9.2 & 28.1 & 37.7 \\
\hline
\end{tabular}

Catalysts $\mathrm{H}_{2}$ reduced at $300{ }^{\circ} \mathrm{C}$ for $2 \mathrm{~h}$.

a Yield $=$ conversion $\times$ selectivity $/ 100$.

ture-sensitive [17]. The Pt-Sn alloy particles may exist on $\mathrm{Pt}-\mathrm{Sn} / \gamma-\mathrm{Al}_{2} \mathrm{O}_{3}$, but are too small to either enhance $\mathrm{C}=\mathrm{O}$ hydrogenation or inhibit $\mathrm{C}=\mathrm{C}$ hydrogenation. However, the formation of large Pt-Sn alloy particles also reduces the dispersion of $\mathrm{Pt}$, so that the activity of hydrogenation decreases. Therefore, a higher $\mathrm{H}_{2}$ reduction temperature gave higher crotyl alcohol selectivity but resulted in a low conversion of crotonaldehyde hydrogenation (Table 3).

The improved selectivity of crotyl alcohol in crotonaldehyde hydrogenation is proposed schematically in Fig. 9, which displays a $\mathrm{PtSn} / \mathrm{SnPt}_{3}$ particle with surface $\mathrm{Sn}^{n+}$ on BN support. The surface $\mathrm{Sn}^{n+}$ behaves as a Lewis acid site attracting the $\mathrm{C}=\mathrm{O}$ group of a crotonaldehyde molecule. The nearby $\mathrm{Pt}$ can supply the absorbed hydrogen to conduct the hydrogenation of the $\mathrm{C}=\mathrm{O}$ bond, instead of the $\mathrm{C}=\mathrm{C}$ bond. The negligible interaction of $\mathrm{BN}$ and the $\mathrm{PtSn} / \mathrm{SnPt}_{3}$ particle can easily maintain the reduced state of the surface Pt, thus causing weaker adsorbed hydrogen. Such highly active hydrogen facilitates the process of hydrogenation. The partial coverage of $\mathrm{Sn}^{n+}$ on $\mathrm{PtSn} / \mathrm{SnPt}_{3}$ particles also inhibits the hydrogenation of the $\mathrm{C}=\mathrm{C}$ bond.

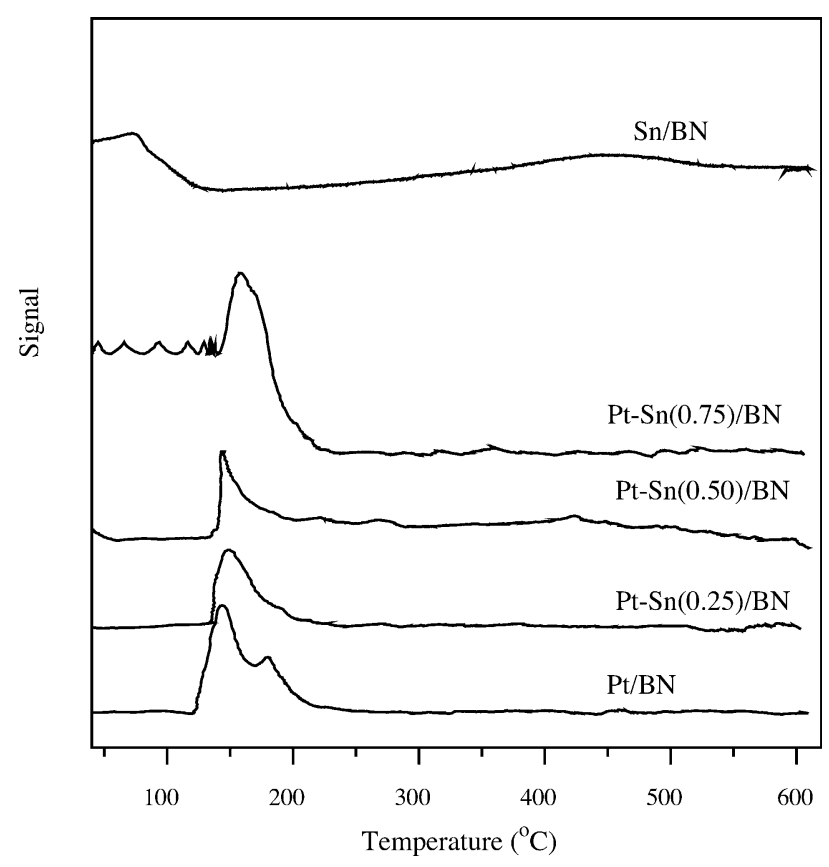

Fig. 8. Temperature programmed reduction of fresh Pt-Sn/BN catalysts.

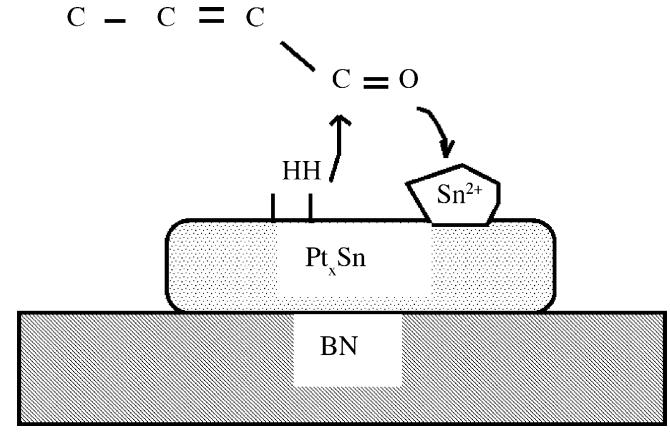

Fig. 9. Schematic mechanism of crotonaldehyde hydrogenation on Pt-Sn/ BN catalyst.

\section{Conclusions}

This study has presented favorable findings for the selective hydrogenation of $\alpha, \beta$-unsaturated aldehyde into unsaturated alcohol by employing BN supported Pt-Sn catalysts. Although butyraldehyde and butanol in crotonaldehyde hydrogenation are favorable based on thermodynamic equilibrium, the product selectivity can be shifted to crotyl alcohol by controlling the reaction kinetics on the Pt$\mathrm{Sn} / \mathrm{BN}$ catalyst. The yield of crotyl alcohol achieved as high as $38 \%$ on $\mathrm{Pt}-\mathrm{Sn}(0.75) / \mathrm{BN}$ at $80^{\circ} \mathrm{C}$. Moreover, crotyl alcohol selectivity reached $80 \%$ at a conversion of $10 \%$ near $40{ }^{\circ} \mathrm{C}$. Boron nitride exhibits superior properties, including chemical inertness, thermal stability and minimum metalsupport interaction. Therefore, boron nitride is a promising support for selective hydrogenation catalyst.

\section{Acknowledgment}

The authors would like to thank the National Science Council of the Republic of China, Taiwan for financially supporting this research under Contract No. NSC-93-2214E-002-030.

\section{References}

[1] P. Gallezot, D. Richard, Catal. Rev.: Sci. Eng. 40 (1-2) (1998) 81.

[2] M. Consonni, D. Jokic, D. Yu Murzin, R. Touroude, J. Catal. 188 (1999) 165. 
[3] F. Ammari, J. Lamotte, R. Touroude, J. Catal. 221 (2004) 32.

[4] Y. Pei, H. Hu, J. Fang, M. Qiao, W. Dai, K. Fan, H. Li, J. Mol. Catal. A: Chem. 211 (2004) 243.

[5] P. Concepción, A. Corma, J. Silvestre-Albero, V. Franco, J.Y. ChaneChing, J. Am. Chem. Soc. 126 (2004) 5523.

[6] F. Coloma, A. Sepúlveda-Escribano, J.L.G. Fierro, F. RodríguezReinoso, Catal. Appl. A: Gen. 136 (1996) 231.

[7] D.I. Jerdev, A. Olivas, B.E. Koel1, J. Catal. 205 (2002) 278.

[8] S. Alkoy, C. Toy, T. Gonul, A. Tekin, J. Eur. Ceram. Soc. 17 (1997) 1415.

[9] Z.-A. Lin, J.C.S. Wu, J.-W. Pan, C.-T. Yeh, J. Catal. 210 (1) (2002) 39.

[10] J.C.S. Wu, Y.-C. Fan, C.-A. Lin, Ind. Eng. Chem. Res. 42 (14) (2003) 3225.
[11] J.C.-S. Wu, Z.-A. Lin, J.-W. Pan, M.-H. Rei, Appl. Catal. A: Gen. 219 (2001) 117.

[12] C.H. Yang, J.G. Goodwin Jr., J. Catal. 78 (1982) 182.

[13] Powder Diffraction File, Card No. 35-749, International Center for Diffraction Data, Newton Square, PA, USA.

[14] F. Coloma, J. Llorca, N. Homs, P. Ramírez de la Piscina, F. RodríguezReinoso, A. Sepúlveda-Escribano, Phys. Chem. Chem. Phys. 2 (2000) 3063.

[15] N. Homs, J. Llorca, P. Ramírez de la Piscina, F. Rodríguez-Reinoso, A. Sepúlveda-Escribano, J. Silvestre-Albero, Phys. Chem. Chem. Phys. 3 (2001) 1782.

[16] A. Huidobro, A. Sepúlveda-Escribano, F. Rodríguez-Reinoso, J. Catal. 212 (2002) 94.

[17] M. Englisch, A. Jentys, J.A. Lercher, J. Catal. 166 (1997) 25. 